\title{
El café en la Otomí-Tepehua: estrategias campesinas y cadenas globales de valor en México, 2017-2018
}

Jozelin María Soto-Alarcón, Profesora Investigadora, Universidad Autónoma del Estado de Hidalgo. Email: jmsoto@uaeh.edu.mx. ORCID_ID: 0000-0003-3931-9310

Diana Xóchitl González Gómez; Profesora Investigadora, Universidad Autónoma del Estado de Hidalgo. ORCID_ID: 0000-0003-3062-9961

Miguel Carrillo Salgado, Profesor Investigador, Universidad Intercultural del Estado de Hidalgo-Tenango de Doria. ORCID_ID: 0000-0002-8326-9958

Fechas del Artículo:

Recibido: 30/01/2020

Dictamen: 05/05/2020

Aceptado: $25 / 09 / 2020$

Publicado: $30 / 10 / 2020$
Forma de citar este artículo: Soto J., González D. y Carri-

Ilo M., (2020). El café en la Otomí-Tepehua: estrategias

campesinas y cadenas globales de valor en México, 2017

-2018, Revista Científica de Estudios Urbano Regionales

Hatsö-Hnini, Vol 1 No. 3 pp.3-48, DOI https://

doi.org/10.47386/2020V1N3A1

\section{Resumen}

En México el cultivo de café es estratégico para la economía campesina y globalizada. El artículo analiza estrategias campesinas y cadenas globales de valor asociadas al café en la región Otomí-Tepehua del estado de Hidalgo. Técnicas de observación participante y entrevistas a profundidad son empleadas para recolectar información. En la región, los cafeticultores enfrentan un entorno productivo adverso; con limitada infraestructura, apoyo institucional y organización colectiva, se vinculan a cadenas de intermediación global con baja remuneración. El trabajo familiar y las estrategias campesinas diversificadas en la milpa, el cafetal y el chilar posibilitan la continuidad del cultivo. Procesos cooperativos representan una alternativa para generar rentas en mercados de café de especialidad.

Palabras clave: Economías diversas; café; estrategias campesinas; cadenas globales de valor

\section{Abstract \\ In Mexico, coffee crop is strategic for peasant and globalized economy. The paper discuss peasant strategies and global value chain in Otomi-Tepehua region, in Hidalgo Mexico. We use participant obser- vations and in-depth interviews. Peasant coffee pro- ducers faced adverse environment with limited insti- tutional support, they are related to low add-value chain. Peasant strategies and family work in: milpa, cafetal and chilar enabled the coffee crops continui- ty. Cooperative production is an alternative to pro- duce rents in specialty markets.}

Keywords: Diverse economies; coffee; peasant strategies; global value chain

\section{$\underset{\text { REDMIIDUS }}{\text { IIII||l| }}$}

\section{Introducción}

En México el cultivo de café emplea a más de 500,000 productores de 480 municipios en 14 entidades federativas. En 2016 representó el $0.66 \%$ del PIB agrícola nacional, aunque la volatilidad del mercado y la crisis desatada por la plaga de la roya anaranjada (Hemileia vastatrix), provocaron una reducción acumulada cercana al $50 \%$ de la producción nacional (SAGARPA, 2017). El aromático es la segunda materia prima más importante en el comercio mundial (CEDRSSA, 2014), su expansión se relaciona con diferenciación productiva y comercial, por ejemplo en los cafés diferenciados (Ponte, 2002; Fitter \& Kaplinsky, 2001). La producción del aromático se sustenta en estrategias campesinas (EC) (Kaplinsky, 2004), mientras su comercio es global. En México, una de las características de la siembra de café es el uso intensivo de trabajo campesino, realizado por los integrantes de los hogares sin remuneración, bajo una lógica de subsistencia. El mantenimiento del cafetal y su rentabilidad se asocian con la diversidad de estrategias implementadas por los hogares de acuerdo a sus contextos socioeconómicos y culturales (Cobo \& Paz-Paredes, 2009).

El enfoque de las Cadenas Globales de Valor (CGV) analiza los procesos de producción, distribución y comercio del aromático, la integración vertical y el fortalecimiento de la propiedad privada en un mercado altamente competitivo (Pérez \& Echánove, 2006; Ponte, 2002). La cadena de valor es global por las reglas desplegadas por actores con mayor impacto en la cadena (Pérez, 2011). Mientras las normas del mercado se delimitan en el contexto global, el cultivo de café se realiza en lo local, con es- 
El café en la Otomí-Tepehua: estrategias campesinas y cadenas globales de valor en México, 2017-2018

Jozelin María Soto-Alarcón, Diana Xóchitl González Gómez y Miguel Carrillo Salgado

trategias campesinas situadas en el manejo del cafetal (Bartra, 2006). En este artículo, se examina la relación entre las $\mathrm{EC}$ de cafeticultores de la región Otomí-Tepehua en el estado Hidalgo y la CGV asociada. El análisis se realiza bajo el siguiente esquema: estrategias campesinas-proceso productivo; organización-gobernanza y, rentas- cafés diferenciados.

La hipótesis de investigación señala que las EC de los cafeticultores se reconfiguran desde las necesidades de la CGV del aromático en un proceso dinámico y paradójico. Los nichos de mercado autodenominados alternativos, valorizan ciertas estrategias campesinas y organizativas (Pérez, 2009; Bartra, 2006); mientras los mercados convencionales comercian café sin diferenciación productiva y merman la capacidad de reproducción campesina, se enriquecen a costa del empobrecimiento de las condiciones de vida de los hogares campesinos. En la relación entre lo global y lo local, algunos cafeticultores logran sobrellevar los mercados a través del cooperativismo y su inserción en mercados específicos, mientras otros lo hacen con estrategias limitadas al contexto del hogar enfrentándose con mercados extractivos y de bajos precios. Examinar esta relación más allá de un determinismo de lo global sobre lo local, nos permite reconocer posibilidades de desarrollo en los contextos locales de los cafeticultores.

El enfoque de las CGV y las EC proveen una visión integral de la producción y el comercio de un cultivo que no puede ser captado por el análisis tradicional de oferta y demanda, aun los de competencia imperfecta, ya que construyen una visión separada del productor, los intermediarios y los consumidores. Los estudios enfocados en la maximización de las ganancias no ofrecen herramientas para analizar las estrategias campesinas de los cafetaleros. La relación entre las EC y la CGV ilumina las prácticas campesinas locales y la generación de rentas en la cadena global y en cadenas cortas de comercio con específicos procesos de intermediación.

Para identificar los factores que posibilitan la creación de rentas desde las estrategias implementadas por los campesinos entre el 2016 y 2018, se aplicó observación participante e investigación en colaboración con los cafeticultores. Se realizaron encuestas y entrevistas a profundidad con cafeticultores y actores importantes de la cadena en el contexto del estado de Hidalgo. Para estudiar el ámbito global se integró literatura asociada. En primer lugar, se plantea el marco teórico, seguido de la metodología. En la tercera sección se discuten los resultados para finalmente llegar a las conclusiones.

\section{Las estrategias campesinas de sustento y las cadenas globales de valor del café}

Las estrategias de sustento refieren a las decisiones, acciones y objetivos implementados por integrantes de los hogares para asegurar su sobrevivencia (Radcliffe, 1986). El concepto de estrategia campesina remite a las prácticas de sobrevivencia locales entrelazadas con la esfera económica, política, social y cultural del hogar campesino, que además recrean la vida comunitaria (Vázquez, Vizcarra, Quintanar \& Lutz, 2009). Los hogares campesinos son las unidades de análisis, entidades heterogéneas y jerárquicas, características determinantes en la definición de estrategias (Cobo y Paz-Paredes, 2009). Las EC comprenden las prácticas de mercado encaminadas a la producción-venta y aquellas asociadas con la subsistencia, como la elaboración de alimentos - prácticas de no mercado. Las estrategias de reproducción social diferenciadas por género son fundamentales para los cultivos (Niehof, 2004), ya que posibilitan la producción, comercialización y amplían los procesos de acumulación en los mercados mundiales. La emigración en los hogares es una estrategia campesina utilizada en zonas cafetaleras en México (Cobo y Paz-Paredes, 2009; Ortega y Ramírez, 2013).

Los hogares campesinos mantienen una economía diversa, en la cual recrean diversas formas de trabajos, propiedades, finanzas, transacciones y encuentros con los que sostienen a sus familias (GibsonGraham, Cameron \& Healy, 2013). En las economías diversas el trabajo es remunerado y no remunerado. En los hogares campesinos, la propiedad es privada y colectiva; mientras el acceso a crédito finanzas - no es exclusivo de los mercados bancarios, por ejemplo en las cajas de ahorro y prácticas de redistribución del excedente emprendidas por cooperativas cafetaleras insertas en procesos de comercio justo. Los campesinos realizan transacciones con los intermediarios regionales y en mercados alternativos donde se privilegia la venta directa. Los encuentros en el cafetal entre campesinos y el medio ambiente influyen en la calidad del grano y su resistencia a plagas (Bartra, 2006).

La diversificación campesina es clave para la subsistencia (Ellis, 2000), depende de los activos productivos, la disponibilidad de mano de obra, condiciones ambientales, cercanía y relación con el mercado, acceso a programas gubernamentales, habilidades 
El café en la Otomí-Tepehua: estrategias campesinas y cadenas globales de valor en México, 2017-2018

Jozelin María Soto-Alarcón, Diana Xóchitl González Gómez y Miguel Carrillo Salgado

técnicas y capacitación (Fierros \& Ávila-Foucat, 2017). Debido a la complejidad de las variables consideradas en las decisiones estratégicas campesinas no es posible construir un modelo exclusivo de comportamiento, ni acotado a una racionalidad económica (Cobo y Paz-Paredes, 2009).

En México, Vázquez, et al. (2009) destaca la capacidad de los hogares campesinos para desplegar prácticas heterogéneas y solventar necesidades ambientales, económicas y sociales. Los miembros interactúan con lo urbano de múltiples formas, son jornaleros y empleados en las ciudades como resultado de flujos migratorios desde 1940 (Arizpe, 1985), son productores de pequeña escala (Fierros \& Ávila-Foucat, 2017) y participan en mercados especializados (Calo \& Wise, 2005). La diversificación como estrategia representa una lógica cuya finalidad es reducir riesgos y subsistir (Cobo y PazParedes, 2009).

La CGV del café se caracteriza por su integración vertical y jerárquica. En 1998 las empresas de torrefacción Nestlé y Philip Morris controlaban casi la mitad del mercado internacional del café tostado y soluble, mientras Volcafe y Neumann administraban un tercio del comercio mundial de café verde (Pérez \& Echánove, 2006). Para el 2003 ocho empresas globales controlaban tres cuartas partes del comercio global: Neuman Kafee (Alemania), Volcafe (Suiza), Cargill (Estados Unidos), Esteve (BrasilSuiza), Aron (Estados Unidos), Ed\&F Man (Reino Unido), Dreyfus (Francia) y Mitsubishi (Japón) (Quintero y Rosales, 2014). La gobernanza jerárquica expresa el poder de las firmas para delimitar y observar los criterios de producción-comercio en empresas pequeñas a través de monitoreo, pruebas, inspecciones y certificaciones (Pérez, 2011; Ponte, 2002; Humphrey \& Schmitz, 2001). Acceder a los criterios de producción y certificación es clave para los productores ya que facilita la transacción a pesar de la complejidad de la cadena (Gereffi, Humphrey \& Sturgeon, 2005).

En el mercado de café se distinguen al menos dos cadenas globales: convencionales y alternativas. En la primera, el precio es resultado de la especulación en el mercado de futuros. El segundo refiere a marcas y certificaciones de comercio justo, orgánico, sustentable (Lewin, Giovannucci \& Varangis, 2004). En algunas de las cadenas denominadas alternativas, las necesidades de los actores están incorporadas en los precios mediante un proceso de negociación dinámico entre productores y certificadores, aunque con limitado alcance de mercado y en el bienestar de los cafeticultores (Pérez \& Echánove,
2006). En dichos procesos se incorporan preocupaciones de sustentabilidad ambiental y remuneración justa (Aranda \& Morales, 2002; Martínez, 2002; VanderHoff, 2002).

En ambas cadenas se identifican espacios locales de producción y distribución; y globales vinculados con criterios de calidad y estandarización. En la CGV del aromático, la producción primaria es central, ya que el lugar de producción es insustituible. En cada espacio, los actores despliegan estrategias, mediante complejas redes de producción y comercio (Lee \& Gereffi, 2015). Los eslabones restringen o facilitan el acceso al mercado. Los eslabones comprenden procesos deslocalizados de concepción y diseño, producción, tránsito, consumo, manejo y reciclaje (Padilla \& Oddone, 2016), conectados a través de mercados dinámicos: nacionales, regionales o globales (Oddone, Padilla \& Antunes, 2014).

Aunque la CGV del café es compleja por las relaciones jerárquicas, los productores organizados en empresas asociativas con capacidad para acopiar, procesar grandes cantidades de café y colocarlo en nichos de mercado específicos, enfrentan los vaivenes del mercado (Bartra, 2006). La acción colectiva posibilita la relación con actores importantes de la CGV, les permite acceder a financiamiento, capacitación y participar en mercados mejor remunerados (Bamber \& Fernández-Stark, 2012).

En México, empresas cooperativas como CEPCO y UCIRI en Oaxaca, Majomut y Tzotzilotic Tzobolotic en Chiapas y Tosepan Titataniske en Puebla han desarrollado estrategias para mejorar la producción, acceder a créditos y comercializar café de Comercio Justo. Los destinos del comercio son Europa, Estados Unidos y Japón. La organización destaca la agencia de los productores para asociarse principalmente entre cafeticultores indígenas, generar reglas de autogobierno y sobreponerse a las inequidades del mercado local y global (Pérez \& Echánove, 2006; Raynolds, Murray \& Leigh, 2004; Aranda \& Morales, 2002; Martínez, 2002; VanderHoff, 2002). Las cooperativas comparten historias de lucha por la apropiación del proceso productivo y comercial (Nigh, 2002). Entre sus estrategias se encuentran: diversificar la producción primaria, la Tosepan Titataniske cosecha y vende pimienta (Bartra, Cobo \& Paz-Paredes, 2004), definir políticas para redistribuir el excedente, se capitalizan y atienden la desigualdad de género en la producción (Lyon, Mutersbaugh \& Whorten, 2017). La organización cooperativa tiene impacto en los hogares, las cooperativas, las comunidades y las regiones 
Jozelin María Soto-Alarcón, Diana Xóchitl González Gómez y Miguel Carrillo Salgado

(Aranda \& Morales, 2002; Martínez 2002; VanderHoff, 2002). Aunque los procesos cooperativos de organización mejoran los precios para los pequeños productores, enfrentan retos de sustentabilidad ambiental, social y financiera (Pérez, 2011).

El entorno institucional de la CGV delimita el cumplimiento de normas y funciona como un sistema de diferenciación productiva y comercial productor de rentas. La renta económica es una prima generada por las barreras de entrada del mercado, procesos de innovación y diferenciación productiva del valor agregado, escasez o singularidad del producto. Las rentas son dinámicas, motivadas por la competencia e innovación y se erosionan al ofertar bienes homogéneos (Kaplinsky, 2000). En la CGV del aromático, la renta económica refiere a la singularidad o diferenciación productiva, reforzada con publicidad para destacar cualidades y/o generar emociones en el consumidor. La publicidad incide en las tendencias de consumo global (Lewin, Giovannucci \& Varangis, 2004).

En las últimas décadas, el consumo del aromático aumentó en tres mercados: cafés diferenciados de alta calidad, café soluble, café y bebidas preparadas; el crecimiento de café convencional es menos dinámico (CEDRESSA, 2014). Estas preferencias acentúan las desigualdades, por un lado, en el comercio de café convencional la gobernanza la conserva la industria de la torrefacción, ya que con su tecnología mezclan cafés de diferentes cualidades para procesar café soluble y, los importadores por el control de inventarios. Ambos actores obtienen elevadas ganancias a pesar de la volatilidad del mercado (Pérez \& Echánove, 2006; Ponte, 2002). Por otro lado, los mercados diferenciados presentan alternativas bajo esquemas delimitados para revalorizar la producción campesina del aromático (Calo \& Wise, 2005; Bartra, 2006).

En los procesos de cambio e innovación, las especificaciones productivas se ajustan a las necesidades del consumidor final en el mercado global. Los cafés de calidad superior son reconocidos, sin embargo, la renta económica aún no se traduce en beneficios sociales 0 al medio ambiente (Giovannucci y Koekoek, 2003). La diferenciación productiva del café comprende: los mercados de cafés gourmet y de especialidad, orgánicos, de comercio justo, ecoamigables o cultivado bajo sombra (Lewin, Giovannucci \& Varangis 2004), los de indicaciones geográficas (IG), las denominaciones de origen (DO) (Marescotti \& Belleti, 2016; Giovanucci, Josling, Kerr, O'Connor \& Yeung, 2009), los responsables y los de código común (Pérez, 2009). Los criterios de diferenciación en estos mercados comprenden: calidad en producción primaria, control administrativo, procesos de comercialización eficientes y equitativos, grado de conocimiento sobre normas ambientales, procesos productivos respetuosos con la biodiversidad, favorecer procesos de educación y capacitación, cuidado de la salud, prácticas laborales justas e involucramiento en proyectos sociales y comunitarios. El mercado de comercio justo es el nicho que satisface el máximo de requisitos. Aunque estos mercados diferenciados no son la "panacea", representan una alternativa para que los productores generen rentas y se apropien de rentas en una CGV compleja (Pérez, 2011).

\section{Metodología}

En la investigación se empleó una metodología cualitativa y se retomaron supuestos de la investigaciónacción. Las entrevistas a profundidad se realizaron a quince hogares de cafeticultores en las comunidades de El Copal y la Huahua del municipio de San Bartolo Tutotepec y Canta Ranas de Huehuetla, de la región Otomí-Tepehua, en Hidalgo, México. El periodo de investigación comprendió de julio de 2017 a agosto de 2018. Los cafetales se visitaron de julio a diciembre de 2017 y entre julio y agosto de 2018. En las entrevistas y la observación participante se abordaron: las labores en el cafetal y la milpa, tipos de propiedad, distribución del trabajo y rentabilidad. Los testimonios se recolectaron por el tercer autor, en periodos de asesoría productiva y comercial con una cooperativa cafetalera. Actores regionales clave en la cadena productiva y comercial fueron entrevistados, entre ellos los representantes del Consejo Hidalguense del Café (Cohicafé), intermediarios locales y empresarios del sector de especialidad en centros urbanos de Pachuca y la Ciudad de México, entre julio y agosto de 2018. La información se sistematizó y analizó destacando la relación entre las actividades remuneradas y no-remuneradas para mantener el cafetal, posibilitar la subsistencia de los hogares y la producción para el mercado, con énfasis en las estrategias campesinas para generar valor en cadenas globales.

\section{El café en la Otomí-Tepehua}

En la región Otomí-Tepehua, los principales grupos indígenas son Tepehuas y Otomíes orientales. La cafeticultura concentra el $49 \%$ del padrón de cafeticultores del estado de Hidalgo (entrevista al Consejo Hidalguense del Café, 2018). El aromático se siembra en territorios de bosque de neblina templados y tropicales montañosos, en sistemas de producción de ladera, con técnicas productivas no mecanizadas, en un sistema agroforestal. Los cafetales 
se ubican en altitudes de 790 a 1200 msnm. La Los hogares destinan en promedio 1.7 hectáreas al siembra del cafeto es acompañada de árboles ma- cafetal, la propiedad es compartida entre el esposo derables de sombra, fijadores de nutrientes en el y la esposa, aunque la mayoría de las mujeres no suelo: el chalahuite (Inga spp), el aíle (Alnus acumi- posee derechos legales. Sólo una familia manifestó nata) y el cedro (cedrela odorata). También se inter- rentar una hectárea para el cafetal. El trabajo camcala con frutales: aguacate, pahua, plátano, mango, pesino es imprescindible en las dos limpias promenogales y cítricos (naranja, mandarina, lima, limón y dio anual. Las actividades del cafetal son una invertoronja). Debido a la diversidad de alturas en la re- sión de mediano plazo, los cafetos no florean en los gión, la temporada de cosecha se extiende a cuatro primeros tres años. Durante 2016, entre los cafetimeses: en la zona baja cosechan de octubre a cultores entrevistados la cosecha disminuyó por la enero y en la zona alta de diciembre a marzo. Para plaga de la roya anaranjada, en consecuencia los la cafeticultura, los hogares campesinos despliegan productores modificaron sus estrategias. Un cafetiestrategias en función de medios de producción, cultor explicó:

integrantes de los hogares, condiciones ambientales y fisiográficas.

Los hogares campesinos emplean trabajo familiar en las limpias, siembra, cosecha y beneficio húmedo y seco del aromático. El $72 \%$ de los miembros del hogar se involucra en las actividades (ver Tabla 1).
"La roya ataca a los cafetos viejos, a los campesinos que no saben trabajar el cafetal les afecta más. Para disminuir el efecto, se limpia el cafetal y si no hay dinero para pagar peón, usamos herbicidas que da la presidencia, esto ayuda para controlar la hierba" (entrevista, El Copal, agosto, 2018).

Tabla 1. Trabajo campesino para el mantenimiento del cafetal ciclo 2016-2017

\begin{tabular}{|c|c|c|c|c|c|c|c|}
\hline Hogar & Integrantes & $\begin{array}{l}\text { Familiares que } \\
\text { laboran en el } \\
\text { cafetal }\end{array}$ & Has & Propietario & $\begin{array}{l}\text { Limpias } \\
\text { anuales }\end{array}$ & $\begin{array}{l}\text { No. de } \\
\text { plantas }\end{array}$ & $\begin{array}{l}\text { Producción } \\
\text { total de café } \\
\text { cereza } \\
\text { (Kilogramos) }\end{array}$ \\
\hline VM & 8 & 5 & 1 & $\begin{array}{l}1 \text { Mujer } \\
1 \text { Hombre }\end{array}$ & 2 & $\begin{array}{l}2000- \\
2300\end{array}$ & 600 a 700 \\
\hline EGS & 2 & 2 & 4 & $\begin{array}{l}1 \text { Mujer } \\
2 \text { Hombres }\end{array}$ & $1-2$ & 6000 & 12000 \\
\hline MGLSA & 4 & 1 & 1 & 1 Mujer & 2 & 2000 & 400 \\
\hline MLSA & 2 & 1 & 1 & 1 Hombre & 1 & 2000 & 400 \\
\hline ATV & 6 & 4 & $21 / 4$ & $\begin{array}{l}1 \text { Mujer } \\
1 \text { Hombre }\end{array}$ & 2 & 3200 & 4000 a 5000 \\
\hline AVSA* & 3 & 2 & 2 & $\begin{array}{l}1 \text { Mujer } \\
1 \text { Hombre }\end{array}$ & 2 & 2000 & 400 a 500 \\
\hline ACM & 4 & 4 & 1 & $\begin{array}{l}1 \text { Mujer } \\
1 \text { Hombre }\end{array}$ & 2 & $\begin{array}{l}900 a \\
1000\end{array}$ & 400 a 500 \\
\hline FRM & 6 & 6 & 2 & 2 Hombres & 2 & 2000 & 3000 \\
\hline LV & 7 & 7 & 2 & $\begin{array}{l}1 \text { Hombre } \\
1 \text { Mujer }\end{array}$ & 2 & 3500 & 4000 \\
\hline
\end{tabular}

Fuente: Elaboración propia con entrevistas a cafeticultores, Julio 2017

* La afectación de la roya en la región no fue uniforme. Por ejemplo, en la familia de AVSA la plaga acabó con los cafetos viejos y la familia tuvo que sembrar nuevos cafetos. En este hogar el volumen de producción es atípico, ya que la mayoría de los cafetos están en etapa de crecimiento. 
Jozelin María Soto-Alarcón, Diana Xóchitl González Gómez y Miguel Carrillo Salgado

La roya llegó a la región en 2013-2014, sus efectos se observaron en la cosecha del 2016. En este periodo, algunos cafeticultores recolectaron 12 toneladas de café cereza, cuando en el 2015 lograron 18 toneladas. En años anteriores la cosecha alcanzaba entre 30 y 32 toneladas en cuatro hectáreas (entrevista a cafeticultor, Canta Ranas, agosto, 2018). Para 2018, los efectos negativos de la roya significaron pérdidas del $32 \%$ al $100 \%$ de la cosecha (entrevistas, diciembre, 2018). La pérdida de dinamismo en la cafeticultura es resultado de la disminución de los precios en CGV convencionales. En el 2017, el kilogramo de café cereza se compró por intermediarios en la región a 12 pesos mexicanos, equivalente a 0.70 dólares estadunidenses (el tipo de cambio promedio en septiembre 2017 fue de 17.83, http://www.banxico.org.mx ), mientras la remuneración por el corte fue de 1.8 a 3 pesos por kilogramo (0.16 dólares). En estas condiciones, los cafeticultores se quedaron con 9 pesos por cada kilogramo para mantener el cafetal y a sus familias (0.50 dólares). Este contexto limita las posibilidades de reproducción campesina de los cafeticultores en comparación con años anteriores. Expresa un productor:

\begin{abstract}
"Cuando había buen precio de café y no había plaga, las ventas eran buenas, con lo que conseguí compré terrenos para seguir sembrando. Ahora, al contrario, solo sembraré una hectárea de las dos que tengo para el café" (entrevista, El Copal, agosto, 2018).
\end{abstract}

En la producción del aromático, el trabajo de los integrantes del hogar es central. Las esposas preparan alimentos, trabajan la hortaliza y cuidan de los animales de traspatio que representan un ahorro en periodo de escasez, ya que el precio del kilogramo de carne osciló entre 25 y 30 pesos mexicanos en 2017. Para las mujeres entrevistadas, su trabajo en el cafetal es una colaboración familiar no remunerada: "ayudo cuando es tiempo de la cosecha del café, en el lavado, secado y selección, al igual que los hijos y las hijas". La división de trabajo por género tiene como finalidad generar medios de vida.

Los cafeticultores además trabajan como cortadores de café en localidades cercanas de los estados de Hidalgo y Puebla. Durante 2017, la recolección de café cereza se remuneró a 1.8 pesos por kilogramo, en un día recolectaron 100 kilogramos y recibieron 180 pesos (aproximadamente 10 dólares). Durante la cosecha, las mujeres trabajan en el secado de la cereza y del café pergamino, exponen los granos al sol en los tendales (planchas de concreto para secar el café), mientras sus esposos van al corte. Aunque el aromático perdió dinamismo en la región, los cafetales se mantienen. La superficie sembrada en el 2000-2001 fue de 3 has promedio y disminuyó a 1.6 has para el ciclo 2016-2017. El rendimiento promedio pasó de 8.4 quintales por hectárea en el ciclo 2000-2001 (López, 2002) a 4 quintales por hectárea en el ciclo 2015-2016 (entrevistas a profundidad, 2017). Para 2018 algunos cafeticultores reportan pérdidas del $100 \%$. Para sostenerse en este contexto, los campesinos se diversifican: son agricultores, jornaleros, se autoemplean como panaderos, comerciantes, ganaderos y carpinteros y también emigran (entrevistas a profundidad, 2017).

La subsistencia de los cafeticultores se entrelaza con otros sistemas productivos: la milpa (parcela con cultivos intercalados: maíz, calabaza, chayote), el chilar y el frijol, además de la ganadería y las actividades del traspatio. Los campesinos distribuyen sus actividades: limpian, cosechan, podan y chapolean (limpieza de la parcela con machete). En todos ellos se intercalan y rotan cultivos. El trabajo en el cafetal es anual, mientras en la milpa las actividades comprenden de junio a noviembre; en el frijol-chilar destinan de enero a febrero y septiembre. Lo producido en los tres espacios provee de alimentos para el consumo del hogar y para los mercados locales: maíz, frijol y chile. A diferencia de las estrategias de diversificación de cooperativas cafetaleras como "Tosepan Titataniske" - siembran pimienta con mayor valor en el mercado global (Pérez, 2009) - en la Otomí Tepehua la producción campesina es de chile y frijol (ver Tabla 2).

El manejo en los tres sistemas demanda conocimientos campesinos, la capacidad de producción depende de la habilidad del hogar campesino para manejarlos. En el encuentro entre campesinos y naturaleza se prioriza la diversidad: en la milpa siembran distintos tipos de maíz, en el chilar y el frijol rotan cultivos, en el cafetal alternan árboles maderables y frutales. La diversidad es una estrategia que involucra al trabajo, al encuentro con la naturaleza y las finanzas.

Los hogares cafetaleros reciben transferencias; las públicas incluyen los apoyos para la producción de café (Pro-Café) y Prospera y Sesenta y más (Programas gubernamentales). Las remesas son transferencias privadas irregulares con las que complementan el gasto doméstico. En un hogar las remesas (enviadas por las hijas), oscilaron entre 15002000 pesos bimestralmente (entre 83 y 113 dólares estadunidenses, septiembre 2017). En esta coyuntura, los campesinos recurren a prácticas de financiamiento local: "cuando no completo el gasto, pido prestado a un amigo, hermano o vecino" (entrevista, 
El Copal, 2018). El cafetal se mantiene, pero se ob- café cereza y café bola- con bajo valor agregado y serva un desplazamiento hacia la ganadería y un lo venden a precios más altos fuera de la región. mayor endeudamiento para alcanzar la subsistencia Según López (2002) el 85\% del comercio regional (entrevistas, La Huahua, 2018).

de café se realizó con intermediarios, entre ellos El procesamiento del aromático involucra la selec- Nestlé y Coscafe. Estas empresas acopiadoras gloción, el corte, el proceso de beneficio húmedo y se- bales controlan la cadena regional de valor.

co, el tostado, molido y presentación final. El precio En la región, el proceso se centra en la comercialiregional es determinante para la agregación de valor zación de café cereza y café bola (ver Tabla 3). El y el escalamiento productivo: si el precio mínimo de café verde es resultado del proceso de beneficio, café pergamino remunera el trabajo campesino in- aunque genera mayor valor a costa de la baja remuvertido en su producción, los productores incremen- neración del trabajo campesino, no tiene mercado tan valor al aromático. Cafeticultores organizados en la región. Los intermediarios no pagan su precio. con capacidad productiva pueden incrementar alre- La torrefacción - tostado y molido - no se realiza en dedor del $500 \%$ el valor de venta, evitando a inter- el ámbito del hogar, sólo los cafeticultores asociados mediarios (Tabla 3).

han logrado conseguir apoyos y/o créditos para adEn 2017, el precio regional del café pergamino osci- quirir maquinaria. La cadena productiva tradicional ló entre 35 y 45 pesos por kilo (entre 1.96 y 2.57 dó- limita a los cafeticultores individuales. Por otro lado, lares estadunidenses). El precio más alto ocurre al el entorno institucional de asociación en la Otomí inicio de la cosecha y el más bajo al final del periodo Tepehua, aunque registra antecedentes de proce(tres meses). Las transacciones de los intermedia- sos organizativos, no muestra resultados favorables rios locales son extractivas, compran café barato -

Tabla 2. Diversificación en los hogares

\begin{tabular}{|c|c|c|c|c|c|}
\hline Actividades/Hogares & Hogar 1 & Hogar 2 & Hogar 3 & Hogar 4 & Hogar 5 \\
\hline \multicolumn{6}{|c|}{ Estrategias de mercado } \\
\hline Producción y venta de café & $\mathrm{x}$ & $\mathrm{x}$ & $\mathrm{x}$ & $\mathrm{x}$ & $\mathrm{X}$ \\
\hline Producción y venta de frijol & $x$ & $x$ & & $x$ & $x$ \\
\hline Producción y venta de chile & $\mathrm{X}$ & $\mathrm{X}$ & & & \\
\hline Producción y venta de caña & & $\mathrm{X}$ & & & \\
\hline Engorda y venta de ganado & & $\mathrm{X}$ & $\mathrm{X}$ & & \\
\hline Producción y venta de tomate y tomate de hoja & & & & $\mathrm{X}$ & \\
\hline Producción y venta de cacahuate & & & & & $\mathrm{X}$ \\
\hline Producción y venta de miel & & $\mathrm{X}$ & & & \\
\hline \multicolumn{6}{|c|}{ Estrategias de no mercado } \\
\hline Consumo de maíz, chile & $\mathrm{X}$ & & $X$ & $\mathrm{X}$ & $\mathrm{X}$ \\
\hline Consumo de productos del traspatio & $\mathrm{X}$ & $\mathrm{X}$ & & $x$ & $x$ \\
\hline Consumo de frijol & $x$ & & & & \\
\hline Trabajo familiar & $x$ & $x$ & $x$ & $x$ & $x$ \\
\hline Crédito familiar & $\mathrm{X}$ & & & $\mathrm{X}$ & $X$ \\
\hline Apoyos gubernamentales & $x$ & $x$ & $x$ & $x$ & $x$ \\
\hline Remesas & $x$ & & $x$ & & $x$ \\
\hline
\end{tabular}

Fuente: Elaboración propia a partir de entrevistas en los meses de enero a diciembre, 2018. 
en la perspectiva de algunos cafeticultores entrevistados:

"Antes participaba en una cooperativa, el beneficio estaba en Tulancingo. No me convenía llevar el café por el costo de transporte, mejor lo tuesto en la casa. Trabajé dos años con la cooperativa y me salí. No vi ganancia" (entrevista, Canta Ranas, agosto, 2018).

No sólo es falta de planeación y desconocimiento de las condiciones de los cafeticultores en la operación de las cooperativas, según los testimonios recolectados por Carrillo (2014), los cafeticultores desconfían de la capacidad de organización. Por ejemplo, en la cooperativa Café Regional Otomí Tepehua S.A. los socios desconfiaron del comité de administración al gestionar recursos públicos y be- neficiar a un limitado grupo. Esta cooperativa operó hasta el 2014, buscaba acopiar y comercializar el aromático con mejores precios. La estrategia de asociación entre cafeticultores muestra una tendencia decreciente, Pérez \& López (2013) identificaron 173 asociaciones cafetaleras legalmente constituidas en 1993, para el 2015 sólo cuatro organizaciones de productores recibieron apoyos gubernamentales en la región.

Al contexto organizativo se suma la débil política pública de fomento. Los subsidios han disminuido en monto y en número de beneficiarios (Subsidios al campo, 2016). La reducción presupuestal impacta en la asesoría técnica regional ya que la realiza un solo extensionista del Cohicafe (entrevista Cohicafe, 2018). El extensionismo se apoya de otros progra-

Tabla 3. Medios de producción y procesamiento: insumo-producto

\begin{tabular}{|c|c|c|c|c|}
\hline $\begin{array}{l}\text { Proceso de } \\
\text { producción }\end{array}$ & Manejo cafetal & Beneficio seco & Beneficio húmedo & Café verde \\
\hline Actores & $\begin{array}{l}\text { Hogar campesino } \\
\text { Pro-Café }\end{array}$ & Hogar campesino & Cafeticultor & $\begin{array}{l}\text { Cafeticultor } \\
\text { Cooperativa }\end{array}$ \\
\hline Insumos & $\begin{array}{l}\text { Trabajo campesino } \\
\text { Plaguicida Fertili- } \\
\text { zantes Semillas }\end{array}$ & $\begin{array}{l}\text { Trabajo campesino habi- } \\
\text { lidad del Cafeticultor } \\
\text { Café cereza }\end{array}$ & $\begin{array}{l}\text { Habilidad del cafeticultor } \\
\text { Café cereza }\end{array}$ & $\begin{array}{l}\text { Habilidad cafeticultor } \\
\text { Café pergamino }\end{array}$ \\
\hline Actividades & $\begin{array}{l}\text { Siembra } \\
\text { Limpias Cosecha } \\
\text { Selección de grano } \\
\text { Duración anual } \\
\text { (cuadro 2) }\end{array}$ & $\begin{array}{l}\text { Extender el café cereza } \\
\text { sobre tendales a la luz } \\
\text { del sol. Mover el grano } \\
\text { para su secado de cua- } \\
\text { tro a cinco semanas. } \\
\text { Cuidar en periodo de } \\
\text { lluvias }\end{array}$ & $\begin{array}{l}\text { Despulpar el grano con maquinaria. Qui- } \\
\text { tar la carne de la semilla y eliminar la } \\
\text { pulpa. Seleccionar los granos y lavarlos } \\
\text { en un tanque. Iniciar el proceso de fer- } \\
\text { mentación. Después de tres días se } \\
\text { separa el mucilago. Posteriormente, se } \\
\text { seca sobre el tendal y mueven cada } 12 \\
\text { horas durante cuatro días para secar } \\
\text { homogéneamente }\end{array}$ & $\begin{array}{l}\text { El café pergamino se } \\
\text { trilla y obtiene el café } \\
\text { almendra o café verde }\end{array}$ \\
\hline $\begin{array}{l}\text { Medios de } \\
\text { producción }\end{array}$ & $\begin{array}{l}\text { Aperos de labranza } \\
\text { Parcelas }\end{array}$ & Tendales & $\begin{array}{l}\text { Máquina despulpadora, } \\
\text { Tanque de lavado-pileta, tendales. }\end{array}$ & Trilladora \\
\hline $\begin{array}{l}\text { Tipo de pro- } \\
\text { piedad }\end{array}$ & Privada aparcería & Privada-Hogares & Privada-Hogares & $\begin{array}{l}\text { Privada-Hogares y } \\
\text { Colectiva }\end{array}$ \\
\hline Producto & Café cereza & $\begin{array}{l}\text { Café en bola sin despul- } \\
\text { par }\end{array}$ & Café pergamino & Café verde \\
\hline Transacción & Intermediario & $\begin{array}{l}\text { Consumo en el hogar. El } \\
\text { excedente se vende con } \\
\text { intermediarios }\end{array}$ & Venta con intermediario & $\begin{array}{l}\text { Venta directa a consu- } \\
\text { midor final }\end{array}$ \\
\hline $\begin{array}{l}\text { Valor agrega- } \\
\text { do }\end{array}$ & Fruta & Grano seco & Grano despulpado y seco & Grano trillado \\
\hline $\begin{array}{l}\text { Precio región } \\
2017\end{array}$ & $\begin{array}{l}12 \$ \text { por kilogramo } \\
\text { ( } 0.67 \text { dólares) }\end{array}$ & $\begin{array}{l}18 \text { \$ por kilogramo } \\
\text { (1.23 dólares) }\end{array}$ & $\begin{array}{l}\text { 35-45 \$ por kilogramo } \\
\text { (1.96 a } 2.52 \text { dólares) }\end{array}$ & $\begin{array}{l}70 \$ \text { por kilogramo } \\
\text { (3.92 dólares) }\end{array}$ \\
\hline $\begin{array}{l}\text { \% Valor Agre- } \\
\text { gado/ } \\
\text { Espacio* }\end{array}$ & Hogar & $\begin{array}{l}50 \% \\
\text { Hogar }\end{array}$ & $\begin{array}{l}365 \% \\
\text { Cooperativa }\end{array}$ & $\begin{array}{l}583 \% \\
\text { Cooperativa }\end{array}$ \\
\hline
\end{tabular}

Fuente: Elaboración propia con datos de la observación participante 2017-2018.

* El porcentaje de agregación de valor es la diferencia entre el precio regional de acuerdo a su calidad y el precio de la calidad inferior más básica. 
Jozelin María Soto-Alarcón, Diana Xóchitl González Gómez y Miguel Carrillo Salgado

mas públicos: Componente Pro-Café e Impulso Productivo al Café, Programa de Sanidad e Inocuidad Agroalimentaria (PSIA), Programa Especial de Seguridad Alimentaria (PESA), Servicio Nacional de Sanidad, Inocuidad y Calidad Agroalimentaria (SENASICA) y de la Comisión Nacional para el Desarrollo de los Pueblos Indígenas (CDI). La asesoría se centra en el proceso de cosecha: infraestructura para invernaderos, plantas y uso de tecnologías. El paquete tecnológico contempla planta y aperos de labranza (Apoyo a Productores de café, 2018). Sobre la capacitación, un cafeticultor expresó:

"Algunas veces dicen cómo usar los herbicidas, pero cuando no, el líquido no se usa y la roya ataca a los cafetos ¿De qué sirve el apoyo si no explican? Tampoco nos dicen nada cuando traen nuevas semillas" (entrevista Canta Ranas, julio 2017).

A pesar del adverso contexto institucional en la región, algunos cafeticultores se han asociado para mejorar los cafetales, afrontar la crisis de la roya y organizar el proceso productivo y comercial. La cooperativa "Ñu Xahoi" es un ejemplo de asociación, está integrada por quince cafeticultores de las comunidades de San Miguel, La Huahua y Santiago del municipio de San Bartolo Tutotepec; Santa Inés de Huehuetla; San José del Valle, San Francisco La Laguna y Santa María Temaxcalapa del municipio de Tenango de Doria. Iniciaron en el 2010 con el objetivo de mejorar la producción, renovar los cafetales, incorporar valor agregado a través del beneficio húmedo y seco, selección de grano, tostado y molido. Incrementar la capacitación y acceder a mercados mejor remunerados.

En "Ñu Xahoi" la elección del comité ejecutivo es democrática en asamblea cada dos años. En reuniones bimestrales, los socios discuten y evalúan su participación en mercados, las reuniones generan confianza en la cooperativa. La asesoría técnica la realizan dos socios (estudiantes universitarios). También promocionan el aromático en mercados especializados. Algunas de estas actividades fueron financiadas por actores privados externos ("Fomento Social Banamex") en el año 2010. La cooperativa en ocho años ha generado un incipiente proceso de confianza. Las estrategias colectivas comprenden: capacitación a los miembros para la renovación de los cafetos, diagnóstico de cafetales, mejora del acopio colectivo a través de una bodega común, procesamiento mediante la torrefacción con maquinaria propia (tostado y molido), diseño de marca y presentaciones comerciales en cafeterías de especialidad en la Ciudad de México. Aunque este mer- cado les representa una posibilidad para vender a mejor precio, la demanda es aún baja. Venden cerca del $50 \%$ con intermediarios y entregas directas. "Ñu Xahoi" ha ganado el control en los tres segmentos de la cadena: renuevan cafetos y limpian el cafetal para controlar la plaga de la roya. En el segmento de la producción se vinculan con actores para adquirir maquinaria e infraestructura. La capacitación y supervisión son constantes con técnicos locales. En la comercialización, privilegian la venta directa en cafeterías de especialidad que aprecian su calidad.

Para generar rentas, la cooperativa se ha centrado en mejorar la calidad del grano. Trabajan en la siembra de plantas libres de roya y en la cosecha de granos maduros. Llevan registros administrativos y productivos para facilitar la trazabilidad en los cafetales. Seleccionan granos de calidad para el proceso de torrefacción. La cooperativa adquirió maquinaria para el beneficio húmedo y seco. En el segmento de la comercialización han invertido en una marca propia para posicionarse en cafeterías locales. Los campesinos cafeticultores y cooperativistas no muestran interés por transitar a la producción orgánica que caracteriza a un segmento de los mercados de especialidad, por el alto costo de renovación de cafetales, tampoco están familiarizados con criterios ecológicos.

Los cooperativistas se interesan por crear fondos de emergencia para cubrir parcialmente servicios médicos y gastos de vivienda. La cooperativa reinvierte el excedente en maquinaria e insumos. La autonomía organizativa se manifiesta en la elección democrática del comité, el trabajo del equipo de supervisión técnica y el desarrollo de una estructura organizativa para el acopio, procesamiento, supervisión de calidad y comercialización del café (entrevistas a técnicos de la cooperativa, diciembre 2017).

Para "Ñu Xahoi" el mercado de especialidades ofrece una alternativa para apropiarse de rentas, sin embargo, la estandarización productiva es un desafío para los hogares con distintos medios de producción; algunos socios tienen mayores posibilidades para especializarse, en otros hogares las condiciones de trabajo son más precarias. La cooperativa ha financiado la compra de paquetes productivos para los socios más necesitados, pero su capacidad de reinversión es limitada. En 2018, la cooperativa administró una bodega común y maquinaria para el trillado, selección, tostado, molido y empacado, tareas realizadas por los socios. Para este año, la cooperativa vendió grano verde de alta calidad a tostadores, la distribución de las ventas se realizó 
Jozelin María Soto-Alarcón, Diana Xóchitl González Gómez y Miguel Carrillo Salgado

bajo criterios de calidad y premió a los cafeticultores con mejor manejo en el cafetal.

\section{Conclusiones}

La discusión de las EC y la CGV inmersas en la producción de café en la región Otomí Tepehua nos permitió identificar actores, medios de producción, acciones y efectos de la cafeticultura en entornos sociales y económicos. La siembra del aromático se entrelaza con sistemas de producción campesina: el chilar, la milpa, el traspatio. Las estrategias de sustento incorporan al trabajo, las finanzas, las transacciones, los encuentros con la naturaleza y los tipos de propiedad. La diversificación de las estrategias campesinas permite a los hogares solventar necesidades de subsistencia y mantener el trabajo campesino, base de la producción cafetalera.

La participación de la región en la cadena global de valor expresa una inserción subordinada y dependiente, con impactos negativos en la producción y la capacidad de sobrevivencia de los hogares campesinos. En este contexto, los campesinos se endeudan y la cafeticultura es desplazada por la ganadería. Las estrategias cooperativas se enfrentan a un entorno regional de desconfianza, limitada asesoría técnica y reducido acceso a programas gubernamentales. Cooperativas como Nu-Xaoi buscan sobreponerse a las dificultades organizativas y la CGV asociada, mejorando la calidad del producto final para comercializarlo en mercados de especialidad local y nacional. Aunque han ganado terreno, los procesos de creación de rentas no son accesibles en el mediano plazo. Incorporar los enfoques de la CGV y las EC, nos permite identificar condiciones situadas de los cafeticultores y las estrategias implementadas para enfrentar las inequidades del mercado global y entornos institucionales. Los programas de apoyo al sector deberían visualizar la interacción entre el cafetal y otros sistemas productivos campesinos, así como favorecer procesos de producción y comercialización generadores de rentas para los cafeticultores de pequeña escala en sus contextos.

\section{Bibliografía}

Aranda, J. \& Morales, C. (2002). Poverty alleviation through participation in fair trade coffee networks: The case of CEPCO, Oaxaca, Mexico. Fair Trade Research Group, Colorado State University.

Arizpe, L. (1985). Campesinado y migración. Secretaria de Educación Pública.

Bamber, P. \& Fernandez-Stark, K. (2012). Supporting the competitiveness. Duke University: Center on Globalization, Governance \& Competitiveness at the
Social Science Research Institute.

Bartra, A. (2006). Virtudes económicas, sociales y ambientales del café certificado. El caso de la Coordinadora de Productores de Café de Oaxaca. En B. Canabal Cristiani, G. Contreras Pérez, \& A. León (Eds.), Diversidad Rural: Estrategias económicas y procesos culturales (pp. 153-202). UAM, Plaza y Valdés.

Bartra, A., Cobo, R. \& Paz-Paredes L. (2004). Tosepan Titataniske. Abriendo horizontes, 27 años de historia. México: Sociedad Cooperativa Agropecuaria Regional Tosepan Titataniske, S. C. L.

Calo, M. \& Wise, T. (2005). Revaluing Peasant Coffee Production: Organic and Fair Trade Markets in Mexico. Global Development and Environment Institute, Tufts University.

Carrillo, M. (2014). Formas de organización y prácticas comunitarias en la producción de café y Tenangos en la Sierra Otomi Tepehua, Hidalgo. Universidad Intercultural del Estado de Hidalgo.

CEDRSSA. (2014). Producción y mercado de café en el mundo y en México. LXII Legislatura Cámara de Diputados.

Cobo, R. y Paz-Paredes L. (2009). Milpas y Cafetales en los Altos de Chiapas. Comisión Nacional para el Conocimiento y Uso de la Biodiversidad.

Ellis, F. (2000). The determinants of rural livelihood diversification on developing countries. Journal of Agricultural Economics, 51(2), 289-302.

Fierros, I. \& Ávila-Foucat, S. (2017). Medios de vida sustentables y contexto de vulnerabilidad de los hogares rurales de México. Revista Problemas del Desarrollo, 48 (191), 107-131.

Fitter, R. \& Kaplinsky, R. (2001). Who gains from product rents as the coffee markets becomes more differentiated? A value- chain analysis. IDS Bulletin, 32 (3), 62-82.

Gereffi, G., Humphrey, J. \& Sturgeon, T. (2005). The governance of global value chain. Review of International Political Economy, 12(1), 78-104.

Gibson-Graham, J-K, Cameron, J. \& Healy S. (2013). Take back the economy. An ethical guide for transforming our communities. Minneapolis: The University of Minnesota Press.

Giovannucci, D. \& Koekoek, F. J. (2003). The State of Sustainable Coffee: A study of twelve major markets. Library of Congress Cataloging.

Giovanucci, D., Josling, T., Kerr, W., O'Connor, B., \& Yeung, M. (2009). Guía de Indicaciones Geográficas. Vinculación de los productos con su origen (1st ed., pp. 157-162). Centro de Comercio Internacional.

Humphrey, J. \& Schmitz, H. (2001). Governance in Global Value Chains. IDS Bulletin, 32(3), 19-29.

Kaplinsky, R. (2000). Globalization and Unequalisation: What can be learn from value chain analysis? The Journal of Development Studies, 34(2), 117-146.

Kaplinsky, R. (2004). Competitions Policy and the Global Coffee and Cocoa Value Chains. Institute of Devel- 
opment Studies.

Lee, J. \& Gereffi, G. (2015). Global value chains, rising power firms and economic and social upgrading. Critical Perspectives on International Business, 11 $(3 / 4), 319-339$.

Lewin, B., Giovannucci D. \& Varangis P. (2004). Coffee Markets. New Paradigms in Global Supply and Demand. Agriculture and Rural Development. Discussion Paper 3.

López, S. (2002). De lo global a lo local: Cambios de cultivos y estrategias de sobrevivencia ante la crisis del mercado internacional del café. El caso de la sierra Otomí-Tepehua en el estado de Hidalgo. Problemas del Desarrollo, 131-162.

Lyon, S., Mutersbaugh, T. \& Whorten H. (2017). The triple burden: the impact of time poverty on women's participation in coffee producer organizational governance In Mexico. Agriculture Human Values, 34, 317-331.

Marescotti, A. \& Belletti, G. (2016). Differentiation strategies in coffee global value chains through reference to territorial origin in Latin American countries. Culture \& History Digital Journal, 5(1).

Martinez, M.E. (2002). Poverty alleviation through participation in fair trade coffee networks: The case of the Tzotzilotic Tzobolotic coffee coop. Colorado State University, Ford Foundation.

Niehof, A. (2004). The significance of diversification for rural livelihood systems. Food Policy, 29(4), 321-338.

Nigh, R. (2002). Poverty alleviation through participation in fair trade coffee networks. Comments on the implications of the Mexico reports. Colorado: Colorado State University, Ford Foundation.

Oddone, N., Padilla R. \& Antunes B. (2014). Metodología del Proyecto CEPAL-GIZ para el estudio de estrategias de fortalecimiento de cadenas de valor. En R. Padilla (Ed.), Fortalecimiento de las Cadenas de Valor como instrumento de la Política Industrial. Metodología y experiencia de la CEPAL en Centroamérica (1st ed., pp. 77-113). Comisión Económica para América Latina y el Caribe.

Ortega, A. \& Ramírez, B. (2013). Crisis de la cafeticultura y migración en el contexto de pobreza y marginación. El caso de los productores indígenas de Huehuetla, Puebla. Ra Ximhai, 9(1), 173-186.

Padilla, R. \& Oddone, N. (2016). Manual para el fortalecimiento de cadenas de valor. Comisión Económica para América Latina y el Caribe.

Pérez, P. \& Echánove F. (2006). Cadenas globales y café en México. Cuadernos Geográficos, 38, 69-86.

Pérez, P. (2009). Los espacios de producción de Café sustentable en México en los inicios del siglo XXI. Revista Pueblos y Fronteras Digital, 4(7), 116-156.

Pérez, P. (2011). ¿Sustentabilidad en la producción cafetalera? Análisis sobre los sistemas alternativos para la producción y comercialización de café. Multidisciplina, 10, 57-76.

Pérez, P. \& López, S. (2013). El café en el Estado de Hi- dalgo: el deterioro de un gran sector exportador. En P. Pérez (Ed), Del sabor a café y sus nuevas invenciones. Escenarios cafetaleros de México y América Latina, (1st ed., pp. 341-367). UNAM.

Ponte, S. (2002). The 'Latte Revolution'? Regulations, markets and consumption in the Global Value Coffee Chain. World Development, 30 (7), 1099-1122.

Quintero, R. \& Rosales, M. (2014). El Mercado mundial del café: tendencias recientes, estructura y estrategias de competitividad. Visión Gerencial, (2), 291-307.

Radcliffe, S. (1986). Gender relations, peasant livelihood strategies and migration: A case study from Cuzco, Peru. Bulletin of Latin America Research, 5(2), 29-47.

Raynolds, L. Murray, D. \& Leigh, P. (2004). Fair Trade Coffee: Building producer capacity via global networks. Journal of International Development 16.

SAGARPA. (2017). Planeación Agrícola Nacional 20172030, Café Mexicano, Ciudad de México: Secretaría de Agricultura.

Subsidios al campo. (2016). http:// subsidiosalcampo.org. $\mathrm{mx/}$

VanderHoff, F. (2002). Poverty alleviation through participation in fair trade coffee networks: The case of UCIRI, Oaxaca, Mexico. Colorado State University, Ford Foundation.

Vásquez, A., Vizcarra I. Quintanar E. \& Lutz B. (2009). Heterogeneidad en las prácticas agrarias como estrategia de adaptación a los procesos globales. Caso de Santa Cruz (Chilapa, Guerrero, México). Convergencia Revista de Ciencias Sociales, 16 (50), 79-106. 